\title{
EXPERIENCE EXCHANGE PROGRAMME CONCERNING THE DOCTORAL STUDIES FROM TWO GERMAN UNIVERSITIES Mihai ANITEI, Nicolae MITROFAN*
}

\section{Abstract}

We had the wonderful occasion of directly coming into contact with the Doctoral Studies organization and the development of the PhD students' training from admission until the final exam at two German Universities, Leipzig University and Jena University. In order for us to form a image as detailed as we can, we have taken into consideration several methods of data selection such as: discussions with the universities' management, with the professors directly involved in the doctoral activity, meetings with $\mathrm{PhD}$ students, access to official documents, visiting the rooms and the research laboratories, etc. In the current article we aimed at briefly showing a part of our experience, starting from the belief that it is useful to all the people involved in the training activity for doctoral studies from the Romanian universities.

\section{University of Leipzig}

\section{A. Main objectives}

During the doctoral studies it is aimed for forming and developing knowledge and competences within the field for the young researchers, as well as moulding a system of values. Therefore, it is expected for the young researchers to manifest the responsibilities in developing the research process and elaborating the report concerning its results, the abilities when working in cooperation with their colleagues and the willingness to participate actively to various seminars and academic activities.

\section{B. Granted titles}

The Faculty of Biosciences, Pharmacy and Psychology from the University of Leipzig is authorized to grant the following titles: doctor rerum naturalium (Dr. rer. nat.), doctor philosophiae (Dr. phil.), doctor paedagogicae (Dr. paed.), for the fields of study of the faculty, as well as the Doctor Honoris Causa title. Within the Doctoral Studies programme from this university interfaculties research programmes are being developed, ensuring for the registered students within this programmes, the same rights and obligations with the other

\footnotetext{
* Mihai ANITEl and Nicolae MITROFAN are university professors PhD at Faculty of Psychology and Educational Sciences, University of Bucharest. E-mail: mihai.anitei@unibuc.ro,nicolaemitrofan@yahoo.com.
} 
$\mathrm{PhD}$ candidates, as well as cotutelle $\mathrm{PhDs}$, when the activity of the $\mathrm{PhD}$ candidate is jointly supervised together with faculties outside Germany. For the latter, the conditions for the programme development are specified in a framework agreement adopted by the two institutions connected through a partnership.

C. The management of the Doctoral Studies is ensured by the Faculty Council, the Doctoral Studies Council (Promotionsausschuss) and the Doctoral Studies Commission (Promotionskommission) which can act in the name of the Faculty Council. The management of the $\mathrm{PhD}$ studies of each candidate is done by a PhD Commission which acts in the name of the Doctoral Studies Council. The title of doctor is granted after successfully completing a written thesis (Dissertation), after a public presentation of the thesis and promoting an oral exam (Rigorosum).

D. Registering the $\mathbf{P h D}$ candidates means the following: a registration request in which the person who wants to be registered writes his intention to obtain a PhD title in a certain field;- the theme of the thesis; - the confirmation letter for coordinating the candidate's activity from the behalf of a professor from within the faculty and from a professor from the joint university;- a declaration stating that the student will respect the regulations concerning the achievement of the PhD title and the principles of the best scientific practices;a linguistic competence certificate in German or English (level B2 according to the Common European Framework of Reference for Languages: Leaming, Teaching, Assessment), only if German is not the candidate's mother tongue.

E. Admission for the process of doctoral examination means achieving the following conditions: -a Masters or Magister university diploma after successfully completing at least four years of full-time courses in an area of study relevant for the field of the thesis or after taking a state exam;- a written thesis;- a written thesis that a professor from a faculty has officially agreed to evaluate it;- the candidate has not participated and has not been rejected in the past to an examination process for the doctoral studies admission and is not undergoing a process of this kind;-a criminal record certificate. Very important: the PhD candidates must prove that they possess the knowledge and competences that ensure the successful completion of the examination process within the Doctoral Studies.

F. The registration file for the evaluations from the doctoral studies programme must contain: -three covered copies of the thesis and 20 copies of the thesis abstract (abstract, results and conclusions) both in German and English; - curriculum vitae and a list of all the exams taken;- the list of the academic publications and lectures; - the proof of obtaining 10 credit points for the academic qualification; - references for naming the examiners; - the proof for obtaining the diploma of studies relevant to the chosen area for the thesis as well as promoting the additional exams for the qualification; - a criminal record certificate; -a declaration which states the fact that the rules are known and 
accepted in order for the $\mathrm{PhD}$ diploma to be obtained. The candidate must add a declaration which states that the presented thesis is the result of his/her work, incorporates his/her own ideas and conclusions, has never been presented in order to obtain the PhD title or any other scientific title at another academic institution, all sources have been cited and clearly indicated; a list of people who offered their helped in elaborating the thesis is added. The requirements concerning the quality of the $\mathrm{PhD}$ thesis are referring to certain aspects such as: reflecting the $\mathrm{PhD}$ student's abilities for conducting his/ her own research projects, the contribution to the subject studied given by the investigations. It is necessary for at least two papers from the thesis to be published.

G. The process of doctoral examination begins once all registration conditions have been accomplished. On the contrary, the candidate is officially announced through a letter conceming the rejection of his/her request, the reasons of the rejection and the possibility of contesting it. Two examiners of the thesis are named, who are trained professors within the field of the thesis, and they write reports in which they express the recommendation for accepting or rejecting the thesis and the conditions in which a rejected thesis can be revised in order to be accepted.

After accepting the thesis, the date for the public presentation is established (no later than six weeks from the moment the thesis was accepted), which consists in a thesis presentation (of maximum 30 minutes) and a discussion starting from the questions the people who are at the presentation (of maximum 20 minutes). The oral examination (Rigorosum) takes place after the presentation and lasts 30 minutes. During this examination the candidate must proof the abilities for integrating his/her subject's thesis in the context of the most recent scientific developments. The candidate decides whether the oral examination is public or not. After the examination, a grade is being given, which is included in the global grade for the candidate's performance. The oral examination can be equivalent with the additional exams taken by the candidate during his/her doctoral studies period in a Research Training Group, in an international $\mathrm{PhD}$ programme or similar to this and the candidate has obtained at least ten credit points.

Immediately after finishing the thesis and the oral exam (Rigorosum), the Doctoral Comission decides over the final grade of the candidate. In the case of a failure the candidate has the right to request for a new final $\mathrm{PhD}$ exam. The general average for the $\mathrm{PhD}$ exam is the average grade of the scores obtained for both reports of the examiners and the average grade of the scores obtained for the presentation and the oral exam (Rigorosum). The average grade can be:

summa cum laude -1.00

magna cum laude $-\geq 1.0-1.5$

cum laude $\rightarrow>1.5-2.5$

rite $->2.5$ 
"Summa cum laude" is granted only when the average grade of all the scores is 1,00 and the Doctoral Commission's members have decided in majority concerning the results of the presentation and the oral exam (Rigorosum). The Faculty Council decides granting the title of doctor and the candidate is announced in a letter about this decision. Receiving the diploma gives the candidate the right to use the title of Doktor. The thesis will be published and copies will be given to the university's library in six months after the date when the announcement of granting the title was made.

H. The International Max Planck School of Research in Neurosciences Communication: Function, Structure and Plasticity (IMPRS NeuroCom).

The University of Leipzig offers a unique $\mathrm{PhD}$ programme through The International Max Planck School of Research in Neurosciences Communication: Function, Structure and Plasticity (IMPRS NeuroCom). Within this programme functional, structural and plastic basis of communication are being studied in an integrative and interdisciplinary approach. The IMPRS NeuroCom mission is to offer PhD students multidisciplinary aspects of cognition, psychology and neurosciences involved in communication. The programme is structured in four modules and it gives the $\mathrm{PhD}$ students the possibility of choosing a research subject specific to one of the following four fields:

a) Cognition I: verbal communication, language: the principles of the auditory and linguistic system are studied from a theoretical perspective as well as from an experimental perspective; behavioural and neuroimagistic techniques are used as well as evoked potentials related with the stimulus (ERP), magnetoencephalography (MEG), functional magnetic resonance imaging ( $\mathrm{MMRI}$ ) and images of the nervous tracks (diffusion tensor imaging - DTI); are monitored as being the most recent studies in the field;

b) Cognition II: non-verbal communication, action and interaction: within the module the motor cognition, the neural mechanisms of visual attention, the ontogenesis of communication and early language and musical communication are being studied; psychological and neural processes which sustain the forms of non-verbal human communication are also being studied.

c) Neurosciences: fundamental and clinic: this module's objective is that of forming the students' ability for using advanced techniques in order to try to understand the brain, both in normal and pathological conditions; there are used complex techniques such as functional and structural magnetic resonance (MRI), electroencephalography

(EEG), 

spectroscopy (NIRS).

d) Methods: the most used modern techniques of neuroimagistic, biophysics and signal processing are: the functional and structural magnetic resonance (MRI), electroencephalography (EEG), and magnetoencephalography (MEG) near-infrared spectroscopy (NIRS).

IMPRS NeuroCom proposes an interdisciplinary approach and after finishing the studies, the students must achieve enough knowledge, abilities and become an innovative spirit which will ensure them the access to a successful career in the field of neurosciences and beyond this. The multidisciplinary aspect of this $\mathrm{PhD}$ programme is reflected in the diversity of the professors' training both in teaching and in coordinating the $\mathrm{PhD}$ students: neurobiologists, neuropsychologists, cognitive science specialists, researchers within the medical field, IT specialists, physicists, etc. The teaching activity consists of: lectures, courses, seminars at the Max Planck Institute and at the University of Leipzig. Research studies and papers are organized as colloquys, annual summer schools which are taking place at Leipzig or London and exchange programmes during the final year. The teaching language and for supervision at the IMPRS NeuroCom is English.

Admission to this $\mathrm{PhD}$ programme is based on a diploma Master (or an equivalent qualification) in domains such as linguistics, psychology, psychiatry, neurology, neurobiology, IT, physics or engineering granted by a university internationally acknowledged. An essential element for admission is the experience in research.

Required documents: - a formal letter containing the reasons why the candidate would like to be admitted to the doctoral studies programme at IMPRS NeuroCom; - CV, including the activities and the experience relevant for the candidate's studies; -three names and e-mail addresses of the academic reviewers who agree to support the candidate's request;- the thesis title and abstract; - a copy of the Masters Diploma or an equivalent diploma; - a copy of the TOEFL test or an equivalent certificate of English language skills (only for the non-natives speakers). Also, English courses are accepted, either from the university of origin or from a foreign university; - copies of the transcripts detailing the university-level qualifications and marks and other relevant academic certificates; - list of publications (if this is the case); - the module the candidates would like to be admitted at.

The students who are admitted are offered scholarships for all three years, which ensure a decent living. Each $\mathrm{PhD}$ student is being offered a certain annual budget for all the necessary payments: for participating at conferences, trips or for the training professional abilities courses. In addition, the IMPRS owns a complete equipped common office, full access at the libraries and 
research facilities. The school offers support for aspects like visas, where to live or health insurances.

For each $\mathrm{PhD}$ student a thesis monitoring commission is organized, which is composed of the scientific supervisor (supervises the content of the $\mathrm{PhD}$ project) and two counselors (they support the $\mathrm{PhD}$ students through academic consultancy and recommendations). The counselors have a double role: ensuring a high level coordination and a satisfactory performance of the $\mathrm{PhD}$ student.

In the first year of the $\mathrm{PhD}$ studies programme the methodological competences of the $\mathrm{PhD}$ students are strengthen. They participate to research activities from the Max Planck Institute and the University of Leipzig, to colloquys for $\mathrm{PhD}$ students, to courses and seminars taught by invited professors and short time courses about the general abilities of using the computer, of writing a formal paper and publication of the scientific papers. At the end of the final year, students must present a plan of the $\mathrm{PhD}$ thesis. The IMPRS Council evaluates the PhD student's activity during the first year and the thesis plan and decides if a student will be promoted to the second year of the programme.

The objective of the activities from the second year of doctoral studies is that of gaining thorough knowledge about the latest studies in cognitive research. At the end of the second year students must present a report of the progress registered in the doctoral research. After evaluating the activities during the courses and of the progress in research, the IMPRS Council decides whether a student will be promoted to the third year of study. During the third year, no courses are taught. Students participate to research activities at the Max Planck Institute and at the University of Leipzig, having the opportunity to spend a period of time at the Institute of Cognitive Neurosciences from London, the associate British institution. Also, the $\mathrm{PhD}$ students can study at other foreign research institutions. Each year the summer school led by all the institutions which participate is being organised. In the third year, the summer school offers students the opportunity to present their current research paper to their colleagues and professors.

\section{The Friedrich-Schiller University from Jena}

\section{A. Objectives}

Within this university the Academy of Doctoral Studies (Graduate Academy - GA) was established, which ensures a research environment at a high level for the $\mathrm{PhD}$ candidates in all domains. The Academy of Doctoral Studies offers attractive study programmes in an interdisciplinary approach, opportunities of developing some transferable competences, monitoring the $\mathrm{PhD}$ students' activity by a team of internationally acknowledged members 
from the faculty. Also, dynamic social interactions with colleagues are encouraged. The Academy is led by an Executive Committee: the Scientific Director and two deputies.

The declared objectives of the Academy of Doctoral Studies are: a. Advanced technical level of the people involved and their research; b. Methods for access and transparent procedures selection; c. Teaching specialized knowledge and methodological abilities; d. Teaching transdisciplinary and vocational competences; e. Excellent supervision; f. Adjusting periods for doctoral courses; g. Teaching didactic and monitoring competences; h. Integration and_internationalization in the scientific community; i. Equal opportunities and compatibility between family and science; $j$. Mentoring for graduates.

The transparency and trust at the Friedrich Schiller University from Jena are ensured through the establishment of the Academy of Doctoral Studies which is aimed at controlling and coordinating all the $\mathrm{PhD}$ programmes. Among its tasks, the following are included: establishing some compulsory standards for the activities developed within the doctoral studies programmes, the final objective being the tendency to achieve an internationally acknowledged research status. The Academy of Doctoral Studies ensures a research environment at a high qualitative standard by inviting specialists with high level of experience and young promising researchers, through integrating $\mathrm{PhD}$ students in research associations and creating them the opportunity to benefit from the collaboration with ex $\mathrm{PhD}$ students experienced specialists. Also, the quality of the supervision is emphasized.

B. For PhD admission a Masters diploma is required, except for the gifted students, graduates of the bachelor degree. They are trained for the doctoral studies for a year through an individualized study programme. The selection committees composed of experienced specialists evaluate the study diplomas, the references from the behalf of acknowledged experts within the relevant research area, the quality of the research abstract, possibly together with an oral presentation.

C. The supervision of the $\mathrm{PhD}$ student's activity is ensured by many coordinators, as to reduce the dependence of only one supervisor and in the case of interdisciplinary programmes, coordinators can have different academic trainings. The $\mathrm{PhD}$ student has the possibility to ask for a coach for any nontechnical problems: help in structuring activities, time management, conflict solving, future and career planning.

D. The programme of studies. The period of the doctoral studies is of three years. Funds for scholarships are available. During the study period, the $\mathrm{PhD}$ students must obtain from 20 to 40 credit points and for the final year the $\mathrm{PhD}$ student must focus their attention on finishing the research papers, writing the thesis and to publish and present some studies to (inter)national conferences as well as on their career guidance. The Academy is offering a package of 
courses which will support the research activities of the $\mathrm{PhD}$ student by helping him/ her to achieve a high level of intellectual and professional qualification. In addition to this, the $\mathrm{PhD}$ student is offered the opportunity to individually structure his/her study programme. The courses are structured in such manner that they grant the technical and methodological training in research, general interdisciplinary scientific qualification and key vocational competences (transferable abilities and generic abilities).

The courses are given by professors of the institution, of postdocs or by internationally acknowledged experts.

The scientific interdisciplinary programme is done through:

Scientific lecture series: presentations, seminars, workshops, discussions to which internationally acknowledged experts from all fields are invited. The focus is on current research topics, interdisciplinary subjects of major interest.

Scientist in Residence "SiR": scientist in Residence is a well-known science specialist, with a considerable intellectual charisma, invited to teach lectures, seminars or discussions aimed at stimulating the structure of the intellectual speech in contemporary interesting areas.

Meetings with alumni: discussions with former $\mathrm{PhD}$ students of the Friedrich Schiller University having topics such as: the advantages of the $\mathrm{PhD}$ diploma offered by the University of Jena, what has been useful for their career and what has been an impediment, giving advice for professional guidance.

Through the courses and the activities offered by the doctoral studies programme it is also aimed at gaining useful competences in choosing career and in its development.

E. Equal opportunities. The Academy of Doctoral Studies is committed to respect the principle of gender perspective. Another aim is to increase the number of females in the academic environment by encouraging females to finish the $\mathrm{PhD}$ studies and have an academic career. Events especially for females are organized and special support is offered for the $\mathrm{PhD}$ students with children.

F. The management of quality at the Academy of Doctoral Studies is done on three levels: PhD students level: evaluating the progress registered during the doctoral studies; $-\mathrm{PhD}$ programmes level: certain quality standards are established; - the Academy level: a regular supervision of the process and the results obtained in relation with the established objectives is being done.

\section{Bibliography}

http://imprs-neurocom.mpg.de/imprs/index.html

http://www.jga.uni-

iena.de/fileadmin/soec/media/GA/Promotionsordnungen/ABPO-EN.pdf 